\title{
Loss of Balance between Striatal Feedforward Inhibition and Corticostriatal Excitation Leads to Tremor
}

\author{
(DYael Oran and Ihar Bar-Gad \\ The Leslie and Susan Goldschmied (Gonda) Multidisciplinary Brain Research Center, Bar-Ilan University, Ramat-Gan, 52900, Israel
}

Fast-spiking interneurons (FSIs) exert powerful inhibitory control over the striatum and are hypothesized to balance the massive excitatory cortical and thalamic input to this structure. We recorded neuronal activity in the dorsolateral striatum and globus pallidus (GP) concurrently with the detailed movement kinematics of freely behaving female rats before and after selective inhibition of FSI activity using IEM-1460 microinjections. The inhibition led to the appearance of episodic rest tremor in the body part that depended on the somatotopic location of the injection within the striatum. The tremor was accompanied by coherent oscillations in the local field potential (LFP). Individual neuron activity patterns became oscillatory and coherent in the tremor frequency. Striatal neurons, but not GP neurons, displayed additional temporal, nonoscillatory correlations. The subsequent reduction in the corticostriatal input following muscimol injection to the corresponding somatotopic location in the primary motor cortex led to disruption of the tremor and a reduction of the LFP oscillations and individual neuron's phase-locked activity. The breakdown of the normal balance of excitation and inhibition in the striatum has been shown previously to be related to different motor abnormalities. Our results further indicate that the balance between excitatory corticostriatal input and feedforward FSI inhibition is sufficient to break down the striatal decorrelation process and generate oscillations resulting in rest tremor typical of multiple basal ganglia disorders.

Key words: extracellular recording; fast-spiking interneurons; oscillations; striatum; tremor

Significance Statement

Fast-spiking interneurons (FSIs) play a key role in normal striatal processing by exerting powerful inhibitory control over the network. FSI malfunctions have been associated with abnormal processing of information within the striatum that leads to multiple movement disorders. Here, we study the changes in neuronal activity and movement kinematics following selective inhibition of these neurons. The injections led to the appearance of episodic rest tremor, accompanied by coherent oscillations in neuronal activity, which was reversed following corticostriatal inhibition. These results suggest that the balance between corticostriatal excitation and feedforward FSI inhibition is crucial for maintaining the striatal decorrelation process, and that its breakdown leads to the formation of oscillations resulting in rest tremor typical of multiple basal ganglia disorders.

\section{Introduction}

The striatum is the main input structure of the basal ganglia (BG). Abnormal input to the striatum and/or abnormal processing of information within this nucleus has been implicated in multiple disorders involving abnormal movement such as Parkinson's dis-

\footnotetext{
Received Sept. 29, 2017; revised Nov. 30, 2017; accepted Jan. 5, 2018.

Author contributions: Y.O. and I.B.-G. designed research; Y.O. and I.B.-G. performed research; Y.O. and I.B.-G. analyzed data; Y.O. and I.B.-G. wrote the paper.

This study was supported in part by Israel Science Foundation Grant 743/13 and U.S.-Israel Binational Science Foundation-National Science Foundation Collaborative Research in Computational Neuroscience Grant 2016744. We thank K. Belelovsky for her help with histology, E. Vinner for her help with graphics, and D. Yael, M. Israelashvili and A. Marmelshtein for insightful comments on earlier versions of this manuscript.

The authors declare no competing financial interests.

Correspondence should be addressed to Izhar Bar-Gad, Gonda Brain Research Center, Bar-llan University, RamatGan 52900, Israel. E-mail: izhar.bar-gad@biu.ac.il.

DOI:10.1523/JNEUROSCI.2821-17.2018

Copyright $\odot 2018$ the authors $\quad 0270-6474 / 18 / 381699-12 \$ 15.00 / 0$
}

ease (Bernheimer et al., 1973), Huntington's disease (Graveland et al., 1985), and Tourette syndrome (Kalanithi et al., 2005). The striatum receives input from most of the cerebral cortex, which is organized in multiple parallel limbic, associative, and motor pathways (Alexander et al., 1986). The dorsolateral striatum (DLS) is part of the motor pathway and is organized somatotopically (Cospito and Kultas-Ilinsky, 1981; Ebrahimi et al., 1992). The neurophysiology of the normal striatum and its downstream targets is characterized by uncorrelated neuronal activity in space and time despite that it receives massive converging organized input (Bar-Gad et al., 2003). In different basal ganglia-related disorders, the neuronal activity becomes temporally and spatially correlated within and between the nuclei of the basal ganglia. This common change in correlation hints that at an active striatal-based decorrelation process is maintained during the normal state (Bar-Gad et al., 2003; Bronfeld and BarGad, 2011). 
The striatum is composed of a network of GABAergic spiny projection neurons (SPNs; also termed medium spiny neurons, or MSNs), which constitute the vast majority of the neuronal population (>90\%; Oorschot, 1996). The SPNs receive converging excitatory glutamatergic input from the cortex and thalamus and inhibitory GABAergic input from multiple sources including the SPN collaterals (Tunstall et al., 2002), the globus pallidus (GP) feedback projections (Mallet et al., 2012), and feedforward inhibition from striatal interneurons (Koós and Tepper, 1999; Berke, 2011). The primary source of this feedforward inhibition on SPNs is the parvalbumin positive fast-spiking interneurons (FSIs). FSIs receive numerous direct inputs from the cortex (Bennett and Bolam, 1994) and, despite their low number $(\sim 1 \%$; Luk and Sadikot, 2001), exert powerful feedforward inhibition that can control the spike timing of SPNs (Koós and Tepper, 1999). This feedforward inhibition has been argued to balance the numerically superior cortical and thalamic excitation (Parthasarathy and Graybiel, 1997). A reduced number of striatal FSIs has been associated with abnormal movements in a rodent model of paroxysmal dystonia (Gernert et al., 2000) and in postmortem tissue from human Tourette syndrome patients (Kalanithi et al., 2005). Striatal FSIs may be selectively inhibited using IEM-1460, a blocker of AMPA receptors lacking the GluA2 subunit that are expressed in the striatum solely by these neurons (Magazanik et al., 1997). Previously, injections of IEM-1460 into the DLS were shown to elicit abnormal movements in rodents that were associated with changes in neuronal activity in the striatum and cortex (Gittis et al., 2011; Klaus and Plenz, 2016). Determining how these abnormal movements and neuronal activity are related to those expressed in different basal ganglia-related disorders may help shed light on the common mechanisms underlying normal striatal processing and their breakdown (Buzsáki et al., 1990; Bronfeld and Bar-Gad, 2011).

In this study, we used wireless recording systems and miniaturized motion sensors to explore the detailed kinematic properties of abnormal movements that arise subsequent to IEM-1460 injections in freely behaving rats, and associate these movements with neuronal activity in the basal ganglia. These data provide insights into both the emergence of abnormal movements arising from basal ganglia malfunctions and the mechanisms that normally function to prevent such abnormalities.

\section{Materials and Methods}

Animals. Twenty-four adult rats (Long-Evans, females) weighing $278 \pm$ $22 \mathrm{~g}$ (mean $\pm \mathrm{SD}$ ) were used in this study. The rats had access to food and water ad libitum and were maintained under controlled temperature and a $12 \mathrm{~h} \mathrm{light/dark} \mathrm{cycle.} \mathrm{All} \mathrm{procedures} \mathrm{were} \mathrm{approved} \mathrm{and} \mathrm{supervised} \mathrm{by}$ the Institutional Animal Care and Use Committee and were in accordance with the National Institutes of Health Guide for the Care and Use of Laboratory Animals and the Bar-Ilan University Guidelines for the Use and Care of Laboratory Animals in Research. This study was approved by the National Committee for Experiments in Laboratory Animals at the Ministry of Health.

Surgery. Four animals were implanted with four injection cannulas (stainless-steel, 25 gauge tube) targeting bilaterally the anterior and posterior DLS. Two cannulas were implanted targeting the anterior DLS (injection target, AP, $1.5 \mathrm{~mm}$; ML, $\pm 2.5 \mathrm{~mm}$; DV, $4.5 \mathrm{~mm}$ ) and two targeting the posterior DLS (injection target, $\mathrm{AP},-0.5 \mathrm{~mm}$; ML, $\pm 3.5 \mathrm{~mm}$; $\mathrm{DV}, 4.5 \mathrm{~mm}$ ). These injection regions were shown previously to be in the forelimb and hindlimb somatotopic regions of the DLS, respectively (Bronfeld et al., 2013). After the implantation, each cannula was sealed with a dummy (stainless-steel, 30 gauge wire).

Twenty animals were each implanted unilaterally (right hemisphere) with a single cannula targeting the same coordinates and custom-made movable bundles of 16/32 Formvar-insulated nichrome microwires
(25 $\mu \mathrm{m}$ diameter; Yael et al., 2013) targeting either the anterior DLS (AP, $0.25 \mathrm{~mm}$; ML, $2.75 \mathrm{~mm}$; DV , $4 \mathrm{~mm} ; N=11$ ) or the GP (AP, $-0.95 \mathrm{~mm}$; $\mathrm{ML}, 3.2 \mathrm{~mm}$; DV, $5 \mathrm{~mm} ; N=3$ ), or both the anterior (same coordinates) and posterior (AP, $-1.25 \mathrm{~mm}$; ML, $2.75 \mathrm{~mm}$; DV, $4 \mathrm{~mm}$ ) DLS $(N=6)$. A similar cannula targeting the primary motor cortex (M1) forelimb somatotopic region (AP, $2.5 \mathrm{~mm}$; $\mathrm{ML}, 2.5 \mathrm{~mm}$; DV, $2 \mathrm{~mm}$ ) was additionally implanted in some $(N=5)$ of these animals (Fig. $1 A$; Israelashvili and Bar-Gad, 2015).

Experimental sessions. The experiments began after a recovery period of at least $7 \mathrm{~d}$ after the surgery. During the experimental sessions, the neurophysiological and kinematic data were recorded continuously while the animal was moving freely in the recording chamber. The neurophysiological signals from the recording electrodes were recorded using either a wired system (amplified 200×; wide bandpass filtered $0.5-10,000 \mathrm{~Hz}$ four-pole Butterworth filter; sampled at $44 \mathrm{kHz}$; AlphaLab SnR, Alpha Omega Engineering) or a wireless system (wide bandpass filtered $1 \mathrm{~Hz}$ single pole to $7000 \mathrm{~Hz}$ three-pole Bessel filter; sampled at $32 \mathrm{kHz}$; Deuteron Technologies). During recordings from the wireless system, kinematic signals were recorded concurrently using a nine-parameter movement sensor covering the $X, Y$, and $Z$ axes of an accelerometer, a gyroscope, and a magnetometer (MPU 9150 InvenSense), and sampled at $1 \mathrm{kHz}$. The recorded signals were synchronized with a video stream (30/60 frames/s; HCW850, Panasonic).

Each experimental session began with recording in the naive state, which was followed by an injection of $0.7-1 \mu \mathrm{l}$ IEM-1460 (Tocris Bioscience) dissolved in artificial CSF to a final concentration of $10 \mu \mathrm{M}$. The solution was pressure injected through an injection cannula (stainlesssteel, 30 gauge tube, protruding $2 \mathrm{~mm}$ from the guide cannula) at a rate of $0.7 \mu \mathrm{l} / \mathrm{min}$ (NE-1000; New Era Pump Systems). A similar method was used to microinject muscimol (Sigma-Aldrich) to M1 $(0.5 \mu \mathrm{l}, 1 \mu \mathrm{g} / \mu \mathrm{l}$, at a rate of $0.5 \mu \mathrm{l} / \mathrm{min}$ ) in five of the animals following the IEM-1460 injection.

Data preprocessing and analysis. The recorded data were preprocessed off-line to extract the local field potential (LFP), multiunit activity and single-unit spike trains (Offline Sorter, version 2.8.8; Plexon). Neurons presenting unstable waveforms or firing patterns were excluded from the database. The remaining neurons were divided into three neuron types (SPNs, FSIs, and GP neurons) according to their recording coordinates, firing rate, firing pattern, and waveform shape. The envelope of the multiunit activity was calculated by filtering the raw signal between 300 and $6000 \mathrm{~Hz}$ followed by a Hilbert transform that was low-pass filtered (400 $\mathrm{Hz}$, four-pole, zero-phase, forward-backward Butterworth filter). All the off-line analyses were performed using custom-written MATLAB code (V2012B; MathWorks).

Oscillation episodes in the LFP signal were detected using a double threshold algorithm: the envelope of the LFP signal in the tremor frequency $(4-10 \mathrm{~Hz}$, four-pole, zero-phase, forward-backward Butterworth filter) was constructed by extracting the instantaneous amplitude using the Hilbert transform and smoothed with a Gaussian window (SD, $350 \mathrm{~ms}$ ). Two thresholds were set relative to the envelopes: (1) the "detection threshold" ( $+1.5 \mathrm{SD}$ above the mean) identified oscillation episodes, and (2) the "refinement threshold" ( +1.2 SD above the mean) was used to define the start and end times of the identified episodes. The gyroscope signal included periods of high-amplitude changes induced by nontremor movement. Thus, identification of oscillation episodes in the gyroscope signal involved the additional stage of calculating the ratio of the magnitude of the tremor-frequency envelope to the magnitude of the envelope of the unfiltered signal. The two thresholds and the resulting tremor episode definition were subsequently calculated on this ratio signal.

The phase coherence between the single-neuron spike trains and the LFP signal was calculated by bandpass filtering the LFP around the primary oscillation frequency $(4-10 \mathrm{~Hz}$, four-pole, zero-phase, forwardbackward Butterworth filter) and extracting the upward zero crossing point in the LFP. Oscillation cycles were defined between two neighboring zero crossing points. Each spike's phase was calculated from the ratio of its temporal locations within the cycle to the overall cycle duration. The phase distribution and the mean phase were calculated using the histogram of the spike phases. 
A

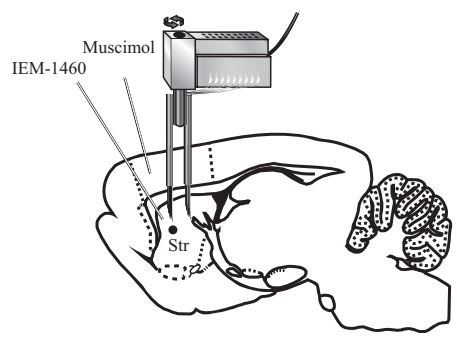

B

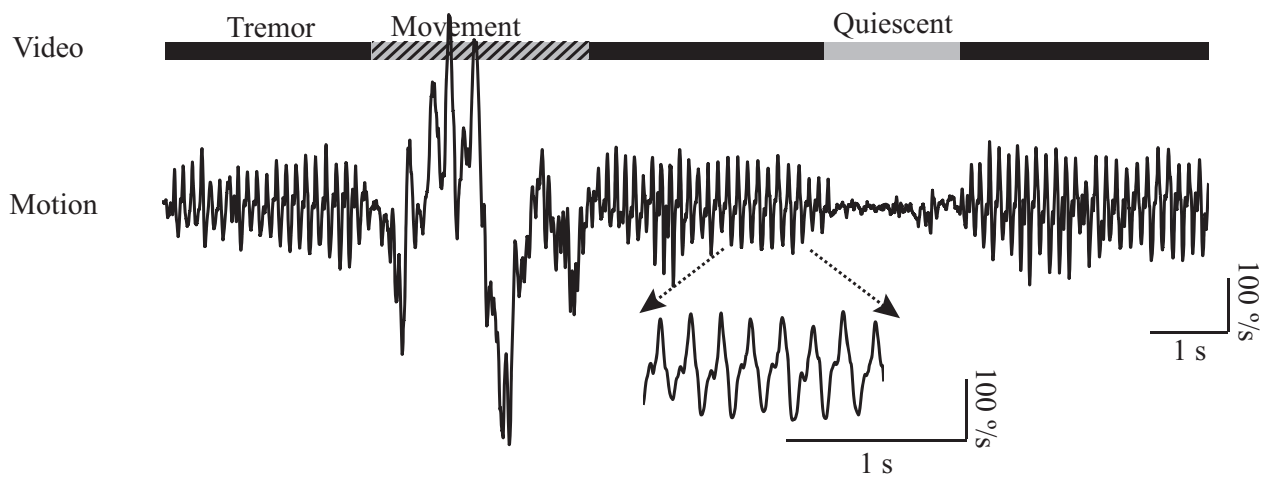

C

D
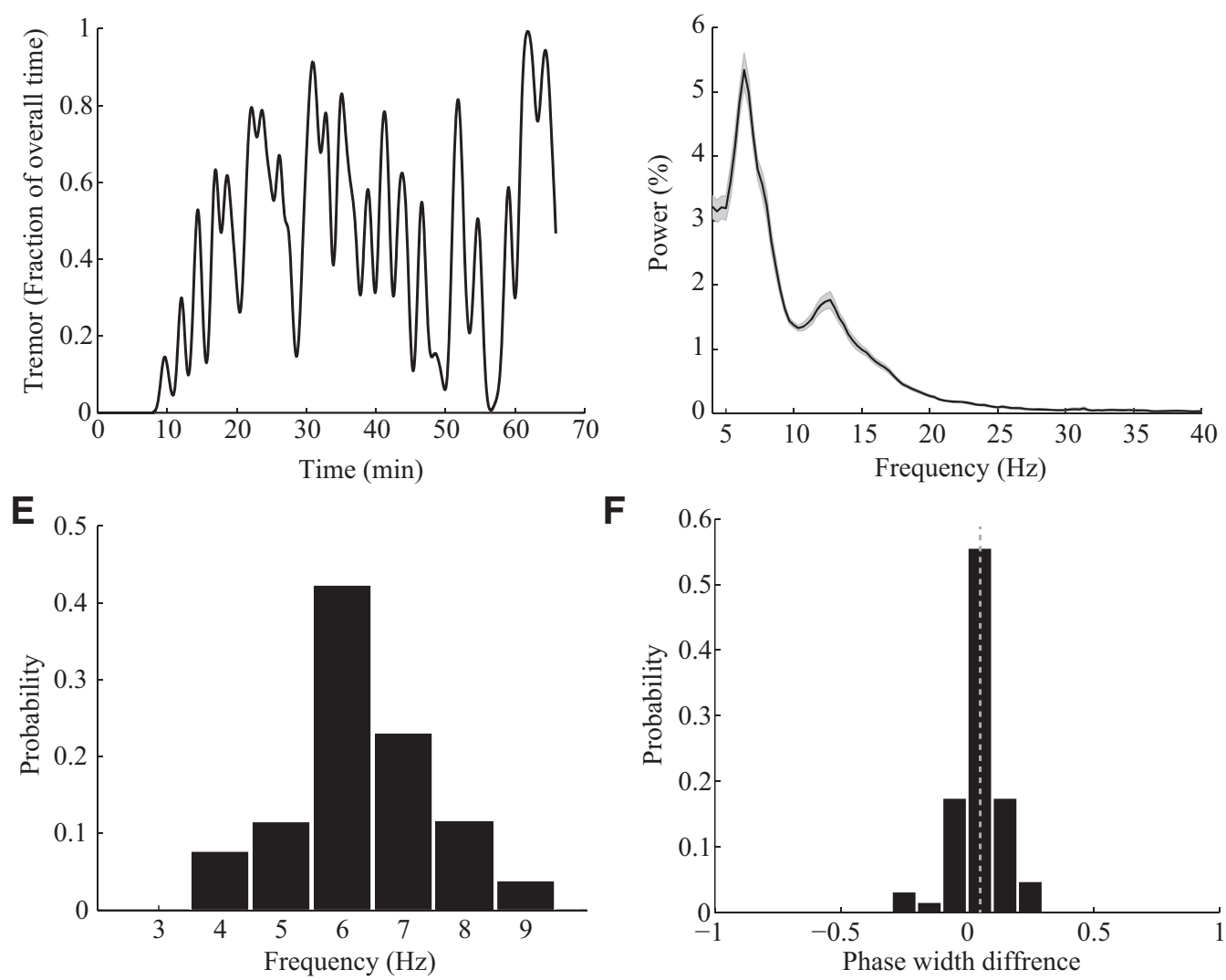

Figure 1. IEM-1460 microinjection in the DLS leads to tremor. A, Schematic diagram of the recording electrodes and injection cannula targeting the dorsolateral striatum (Str) superimposed on a sagittal drawing of the rat brain. $\boldsymbol{B}$, An example of a recording of the angular velocity (gyroscope) signal (bottom) and the associated behavior (top) identified using the simultaneously recorded video stream. $C$, Changes in the fraction of the time in which tremor was expressed throughout an entire session. Time 0 marks the termination of the injection. $D$, Power spectrum of the gyroscope signal across all the sessions (black line, mean; gray background, \pm SEM). $\boldsymbol{E}$, Histogram of main peak frequency in the power spectrum across all sessions. $\boldsymbol{F}$, Oscillation index histogram showing the difference between half cycle durations divided by their sum (dashed line, mean). 


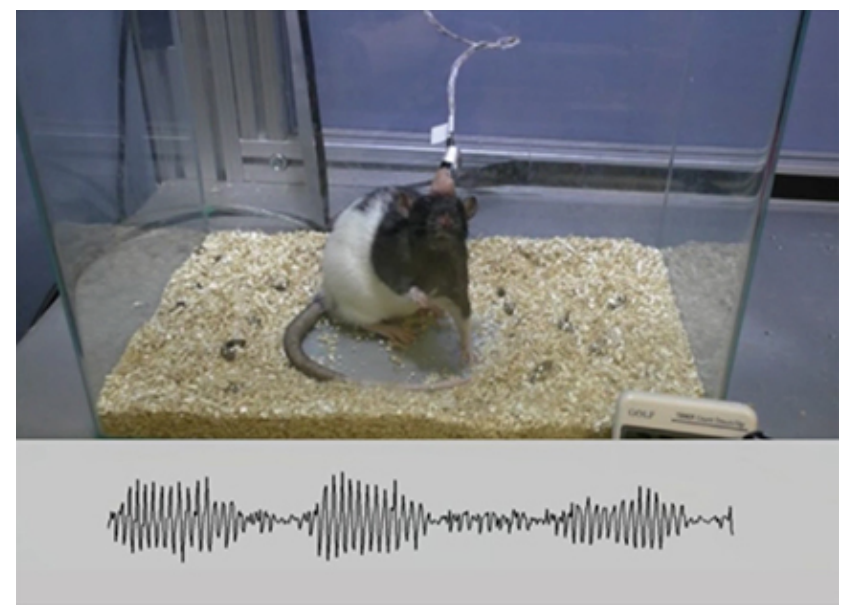

Movie 1. Behavior and LFP signal following IEM-1460 microinjection into the DLS.

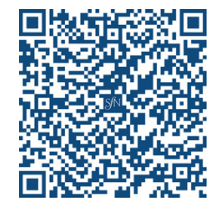

Statistical analysis. The data did not follow a normal distribution; hence, the data from two groups were evaluated either using a Wilcoxon signed-rank test (WSRT) in cases where paired data were available or a Mann-Whitney $U$ test for unpaired data. Comparison of the phases was performed using Kuiper's test to accommodate for cyclic invariance. Values are expressed as mean \pm SD unless indicated otherwise. The significance threshold for the coherence was calculated as $1-(1-$ $\alpha)^{1 /(N-1)}$, where $\alpha=0.99$, and $N$ is the number of consecutive windows used for the coherence calculation (Rosenberg et al., 1989).

\section{Results}

\section{IEM-1460 injection to the DLS leads to the formation of rest tremor}

We injected IEM-1460 unilaterally into the DLS of 24 LongEvans rats in 72 experimental sessions (Fig. 1A). The movement of the rats throughout the sessions was monitored using video and a nine-axis motion ( $X Y Z$ accelerometer, gyroscope, and magnetometer) sensor that was attached to either the head or the forelimb contralateral to the injection site. The microinjection resulted in the appearance of unilateral episodic tremor, which was interspersed with normal behavior including both quiescent and exploration periods (Movie 1, Fig. 1B). The analysis of the video stream indicated that the tremor appeared a few minutes after the injection (7.2 $\pm 2.5 \mathrm{~min}$ ) and lasted over $2 \mathrm{~h}$, making up a variable fraction of the overall behavior throughout the session (Fig. 1C). The tremor, whose details were further quantified using the gyroscope signal (angular velocity), consisted of a narrowband oscillation between 5 and $8 \mathrm{~Hz}$ and contained higher harmonics of the main frequency (Fig. 1D). The distribution of the main tremor frequency across animals was narrow and centered at $6.35 \pm 1.1 \mathrm{~Hz}$ across all sessions (Fig. $1 E$ ). The symmetry of the movement was calculated to differentiate symmetric (e.g., tremor) from asymmetric (e.g., tic) movements. A symmetry index of the oscillation cycle phase duration was defined as the ratio of the difference between the duration of the positive deflection and the duration of the negative deflection divided by their sum. This index showed that the movement was symmetric in its phase duration with a symmetry index of 0.03 (Fig. $1 F$ ).

Additional properties of the tremor episodes were extracted after the identification of tremor episodes using a dou- ble thresholding algorithm and the subsequent segmentation of the gyroscope signal into tremor/nontremor episodes (Fig. $2 A$ ). The tremor episodes did not appear concurrently with normal movement, as was evident when comparing the power of the tremor with the power of low frequencies typical of normal movement during different times within a session. The comparison yielded three clusters: tremor without movement, movement without tremor, and rest without the movement and tremor cluster (Fig. 2B). Within each session, the amplitude of the tremor was narrowly distributed (Fig. 2C), with no evident dynamics in the tremor amplitude within the episode. The duration of each episode $(2.5 \pm 1.2 \mathrm{~s})$ and the intervals between episodes $(4.1 \pm 3.8 \mathrm{~s})$ were stochastic in that both the durations of the episodes (except for very short episodes; Fig. $2 D)$ and intervals between them $(E)$ followed an exponential distribution.

\section{IEM-1460 injection results in oscillatory neuronal activity coherent with the tremor}

Neuronal activity in the DLS was recorded simultaneously with the kinematic signal using 16/32 microwire electrodes (20 animals, 59 sessions). The LFP signal demonstrated episodic oscillations, which appeared concurrently with the ones observed in the motion sensors (Fig. 3A). Segmentation of the LFP and motion signals exhibited the same narrow-band oscillations during the oscillatory episodes of each signal (Fig. $3 B$ ). Coherence between the unsegmented signals reached high values during intermittent episodes on a multisecond time scale (Fig. $3 C$ ). Following the segmentation of the two signals, overlapping segments demonstrated high coherence values at the base frequency and multiple harmonics (Fig. 3D). Analysis of complete sessions across all sessions revealed a primary oscillation frequency in the range of 5-8 $\mathrm{Hz}$ in both the LFP and the motion signal (Fig. 3E), with a wider distribution of coherent frequencies resulting from the harmonics (Fig. 3F).

Neuronal activity in the striatum and the GP was sorted offline into single-unit spike trains that were then classified into neuronal subtypes based on recording location, spike waveform, firing rate, and pattern. The neurons were identified as SPNs $(n=$ $67)$, FSIs $(n=23)$, and GP neurons $(n=32)$. The injection of IEM-1460 led to a significant reduction in FSI firing rates (18 \pm 9.3 to $11.2 \pm 5.7$ spikes/s, mean \pm SEM; $p<0.001$, WSRT), but not to changes in the mean firing rates of the SPNs and GP neurons $(1.8 \pm 1.3$ to $2.0 \pm 1.3$ spikes/s and $20.6 \pm 12.6$ to $21.1 \pm$ 11.4 spikes/s, respectively; mean \pm SEM; $p>0.1$, WSRT; Fig. $4 A$ ). Comparison of the firing rate during the tremor episodes to the rate outside these episodes revealed significant rate changes in the FSIs, but not the SPNs or GP neurons (FSIs, $p<0.01$; SPNs and GP neurons, $p>0.3$; WSRT; Fig. $4 B$ ). Although most of the neurons did not present significant differences in mean firing rates following the injection of IEM-1460, their firing patterns changed dramatically. The firing patterns of the majority of SPNs, FSIs, and GP neurons became oscillatory in the $5-8 \mathrm{~Hz}$ frequency band ( $p<0.001$, WSRT; Fig. $4 C$ ). Moreover, following the injection, the neuronal activity became phase locked to the LFP during the tremor episodes (Fig. 4D). The extent to which the neuronal activity was phased locked to the LFP oscillation was assessed by calculating the phase coherence (see Materials and Methods), the vector sum of the phase distribution (Fig. 4E). The phase coherence following IEM-1460 injection was significantly higher than in the naive state for all neuron types (nonpaired neuronal populations, $p<0.001$, Mann-Whitney $U$ test; Fig. $4 F$ ). The distribution histogram of the mean phase lock- 

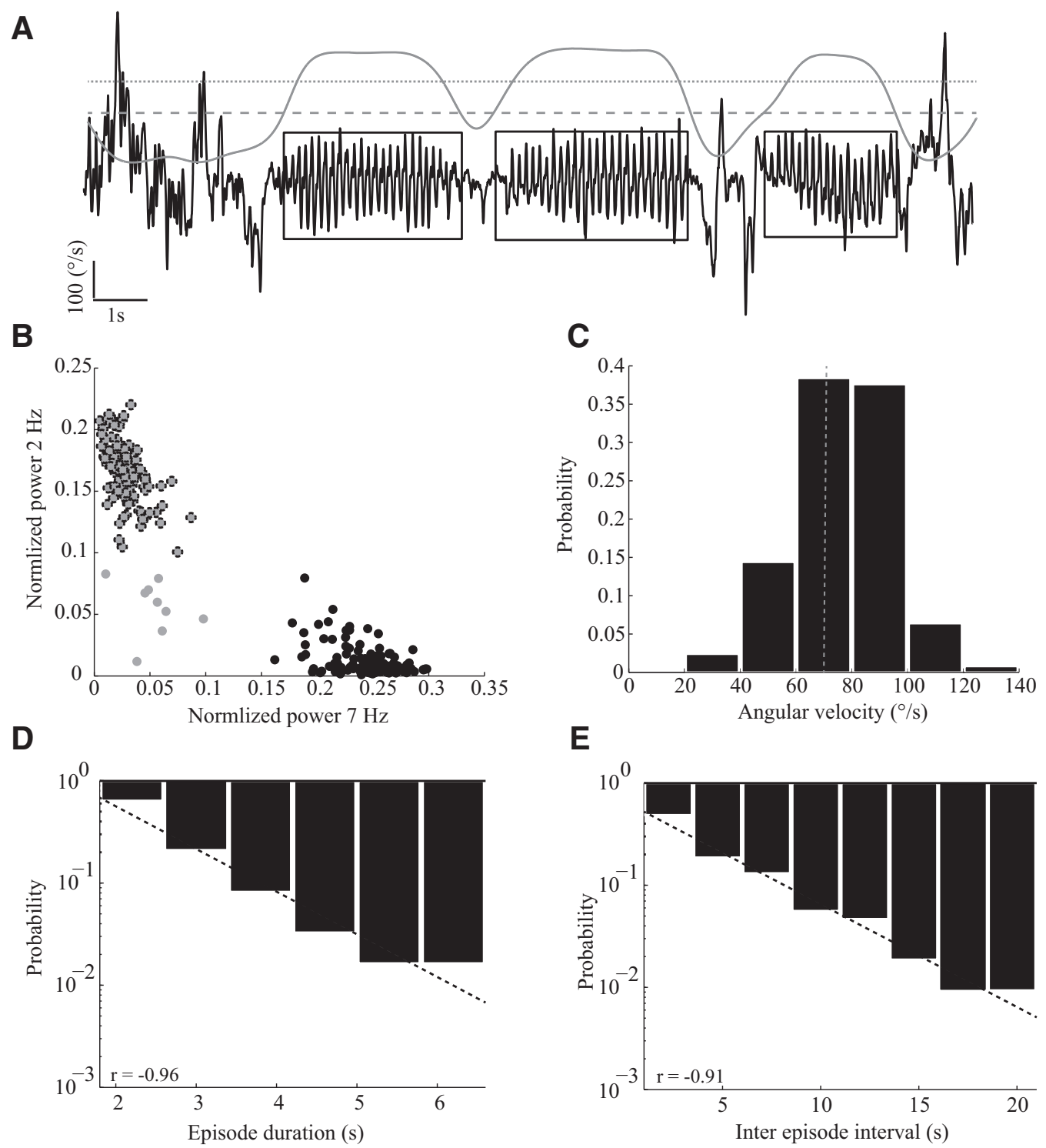

Figure 2. IEM-1460-induced tremor is episodic. $A$, Tremor episode (black boxes) identification using the gyroscope signal (black). The envelope (solid gray) crossing of the upper threshold (dotted line) is refined by the lower threshold (dashed line). $\boldsymbol{B}$, The power of the tremor frequency $(5-8 \mathrm{~Hz})$ oscillations relative to the power of the movement frequency $(1-3 \mathrm{~Hz})$ oscillations during tremor (black) and nontremor episodes (gray). C, Tremor amplitude distribution in a single session (dashed line, mean angular velocity). $\boldsymbol{D}$, Tremor episode duration distribution within a single session (dotted line, exponential fit). $E$, Tremor episode interval (between consecutive episodes) distribution within a single session (dotted line, exponential fit).

ing of neurons across the different neuronal populations was characterized by a narrow distribution illustrating the consistency of phase locking across sessions (Fig. 4G). The mean phase locking was different between SPNs and either GP neurons or FSIs ( $p<0.001$, Kuiper's test), but not between FSIs and GP neurons.

The narrow distributions of the neuronal mean phase locking indicated possible correlated activity between neurons within and between neuronal subtypes. To examine whether this correlation could be attributed solely to the oscillation or to a different nonoscillatory correlated activity, we calculated both the crosscorrelation in the time domain and the coherence in the frequency domain. Coherence analysis between neuronal pairs revealed high values in the $5-8 \mathrm{~Hz}$ frequency band and their harmonics following IEM-1460 injection within and between all the neuronal populations (Fig. 5A). The coherence between striatal neurons (numbers of pairs, SPN-SPN, 93; FSI-FSI, 11; SPNFSI, 31) showed significant coherence values over a broad range of frequencies, in addition to the peaks in the main oscillation frequency and its harmonics, thus hinting at an overall correlated activity. On the other hand, the coherence between GP neurons and other neurons (numbers of pairs, GP-GP, 48; GP-SPN, 45; GP-FSI, 15), both striatal and GP, was dominated by narrow peaks in the main oscillation frequency and its harmonics, thus suggesting a pure oscillatory interaction. Although much of the AMPA-mediated glutamatergic input to the FSIs was blocked by IEM-1460, 90\% of the FSI pairs demonstrated significant coherence, suggesting another source for their coherent activity (Fig. 5B). The cross-correlation functions between neuron pairs evidenced similar changes following IEM-1460 injection. Before the injections, the correlation was flat, with a few shallow wide peaks, especially between SPNs, due to common responses to prolonged behaviors (Fig. $5 \mathrm{C}$ ). Following the injections, the correlation functions displayed multiple peaks typical of oscillatory interactions. However, while the correlations between simultaneously recorded cells in the striatum were high around the zero lag, 

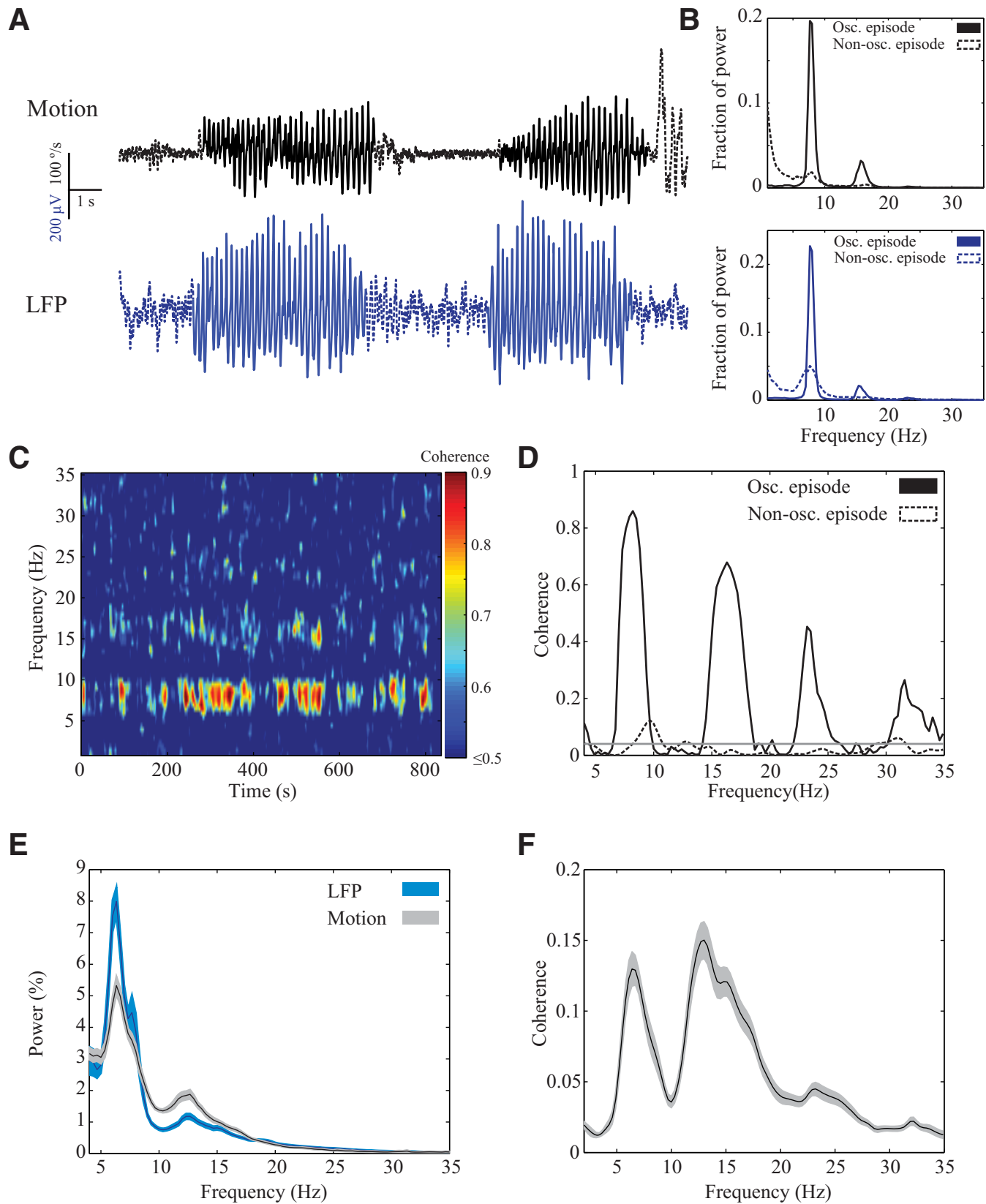

Figure 3. IEM-1460-induced tremor is associated with LFP oscillations. $\boldsymbol{A}, \boldsymbol{B}$, An example of simultaneously recorded gyroscope (black) and LFP (blue) signals ( $\boldsymbol{A}$ ) and their power spectra $(\boldsymbol{B})$. C C Coherence over time between the LFP and the gyroscope signals over a single session. $\boldsymbol{D}$, Coherence between the LFP and the gyroscope signals over the tremor segments (solid line) and during nontremor episodes (dashed line) within a single session (gray line, coherence significance; $p<0.01$ ). $\boldsymbol{E}$, Mean power spectrum of the LFP and gyroscope across all entire sessions (blue/black line, mean; blue/gray background, \pm SEM). $F$, Mean coherence between the LFP and the gyroscope signals over entire sessions across all sessions (black line, mean; gray background, \pm SEM).

which is suggestive of common bursts of activity, the crosscorrelation of the GP neurons with all other cell types did not show this peak, and evidenced only multiple equal-amplitude peaks. This supports the results of the coherence measure that indicated that only the oscillatory activity in the main frequency and its harmonics was evident in the GP without additional correlated activity such as correlated spike bursts unrelated to the oscillations.

\section{Somatotopic organization of the tremor and the related neuronal activity}

The body part displaying the tremor followed a somatotopic organization relative to the injection site within the striatum such that forelimb tremor and head tremor were more commonly induced by injections to the anterior DLS, whereas hindlimb tremor was induced only by injections to the posterior DLS (Fig. $6 A$ ). The relation of the neuronal activity to the somatotopic organization of the tremor was examined using simultaneous recordings in the anterior and posterior DLS following injections to the anterior DLS in five animals during 21 sessions (Fig. $6 B$ ). The LFP in the anterior DLS was significantly more oscillatory than the LFP in the posterior DLS ( $p<0.001$, WSRT; Fig. $6 C$ ). The correlation with behavior was also spatially organized since the coherence between the LFP and the motion signal was significantly higher in the anterior DLS than in the posterior DLS ( $p<0.001$, WSRT; Fig. $6 D)$. 
A

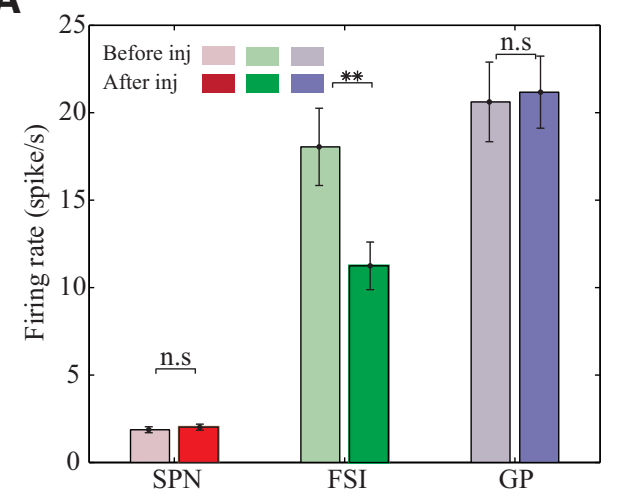

B

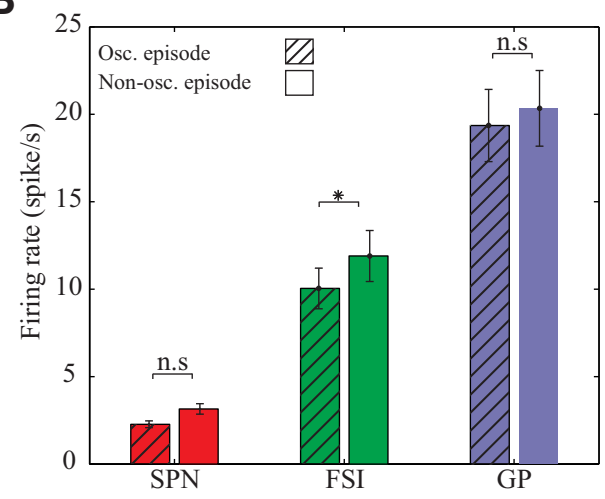

C
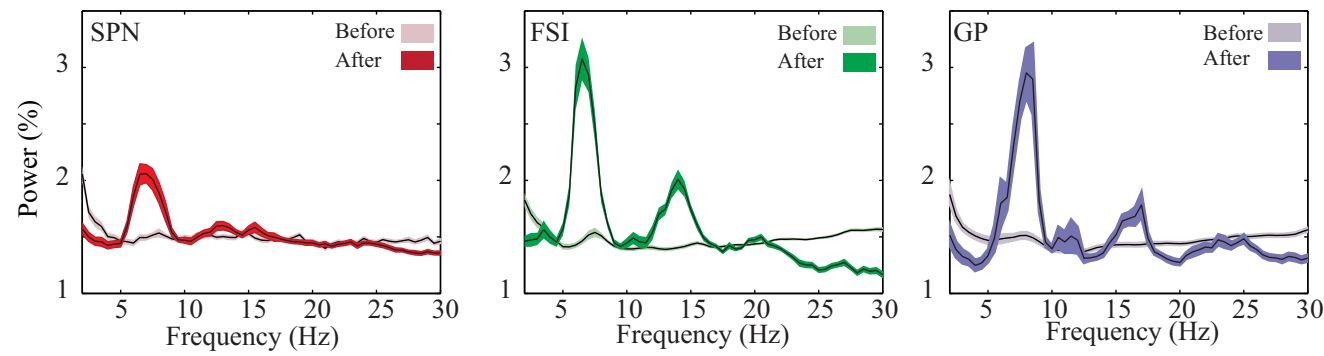

D

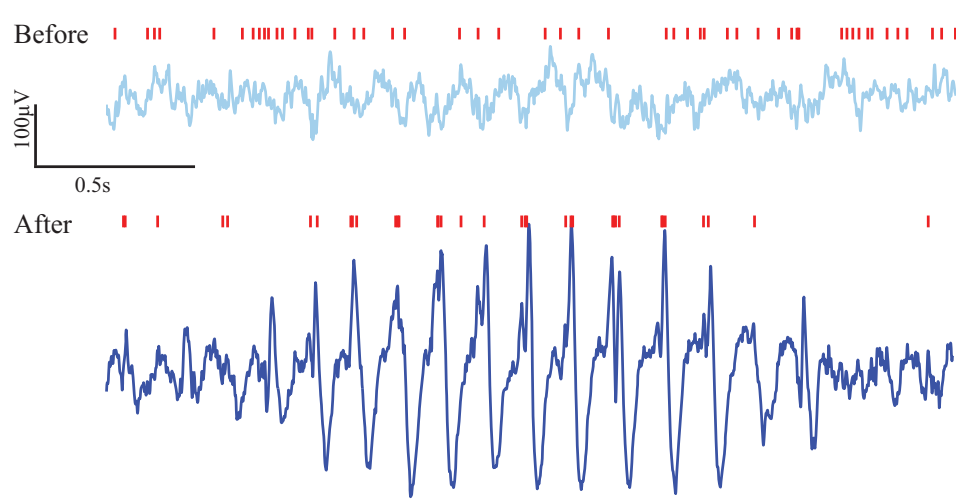

E (i)

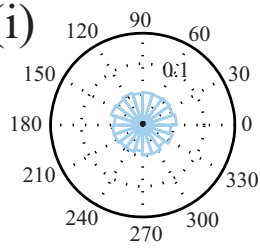

(ii)

$\mathbf{F}$

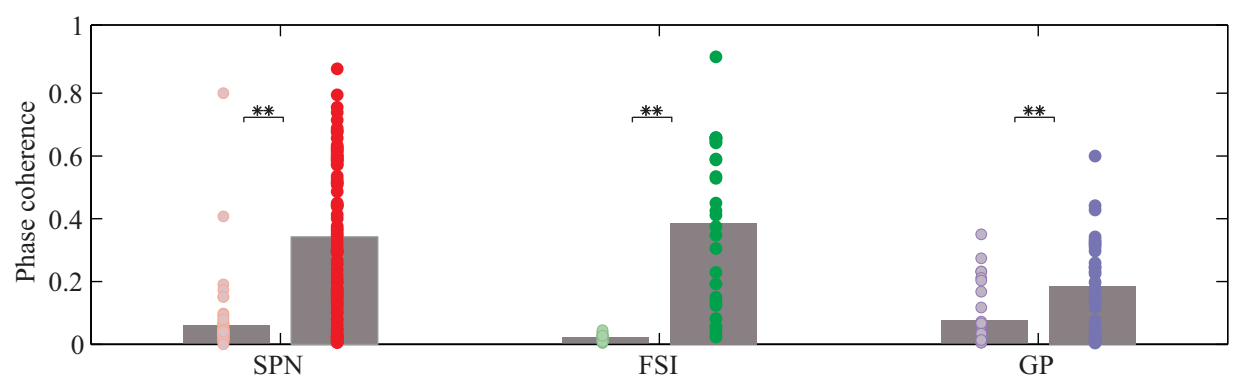

G
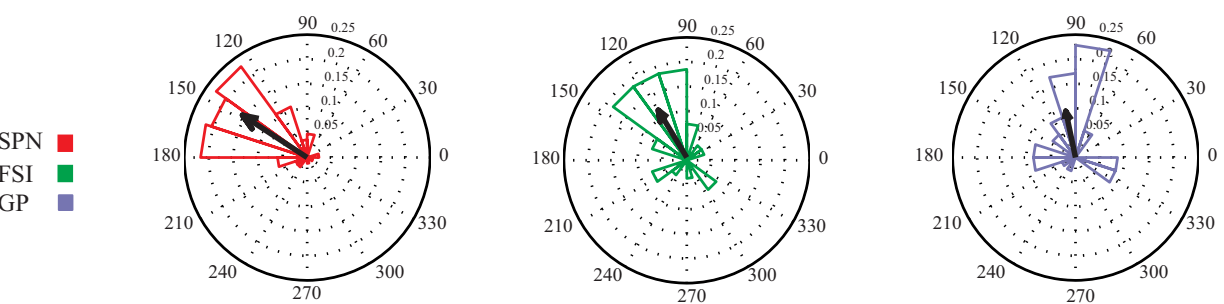

Figure 4. Neuronal activity is phase locked to the LFP oscillations. $A$, Mean firing rate before (light colors) and after (dark colors) IEM-1460 microinjection (inj) for all cell populations. $\boldsymbol{B}$, Mean firing rate during oscillation episodes compared to nonoscillatory periods for all cell populations. C, Mean power spectrum of neuronal activity before (bright colors) and after injection. $\boldsymbol{D}$, An example of a recording of the LFP before (light blue) and after (blue) IEM-1460 microinjection with the concurrent SPN spikes recorded by the same electrode (red). $\boldsymbol{E}$, Phase distribution histogram of an individual cell, before (i; light blue) and after (ii; dark blue) the microinjection. $\boldsymbol{F}$, Phase coherence for each cell population before (light) and after (dark) IEM-1460 microinjection. Each circle represents the phase coherence of a single cell across the entire session. $G$, Distribution of the mean phase locking for each cell throughout the whole session (Figure legend continues.) 
A
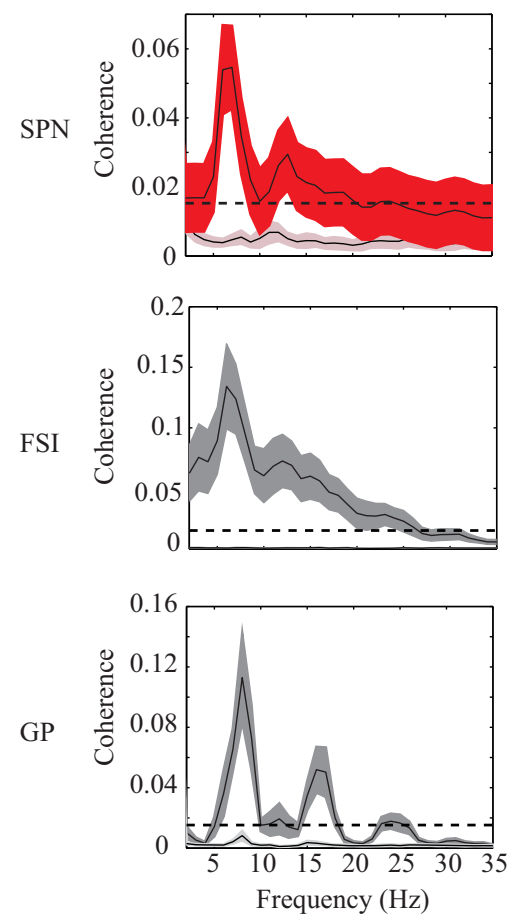

C
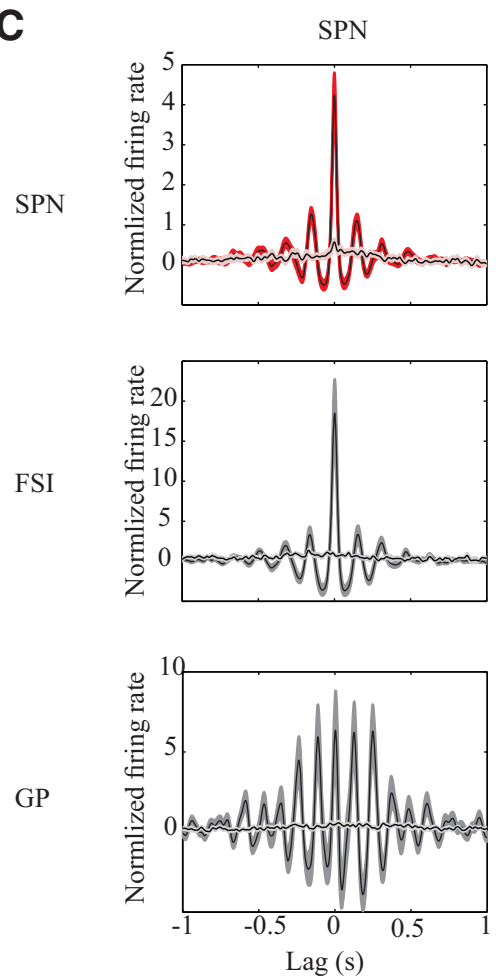
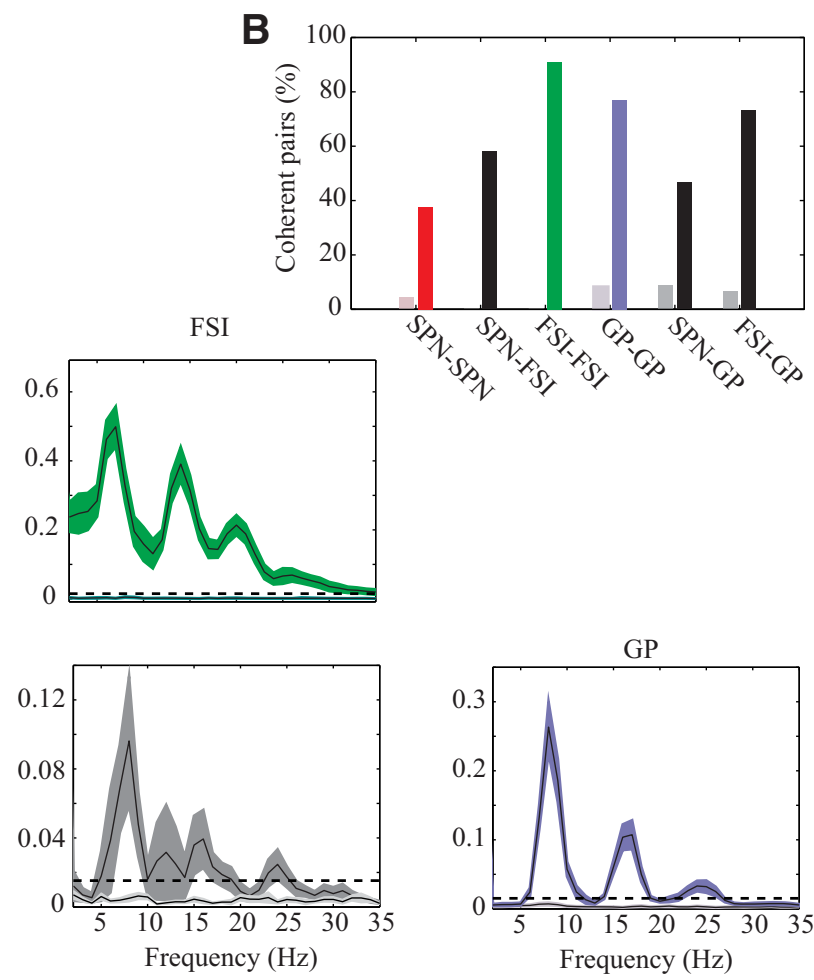

D
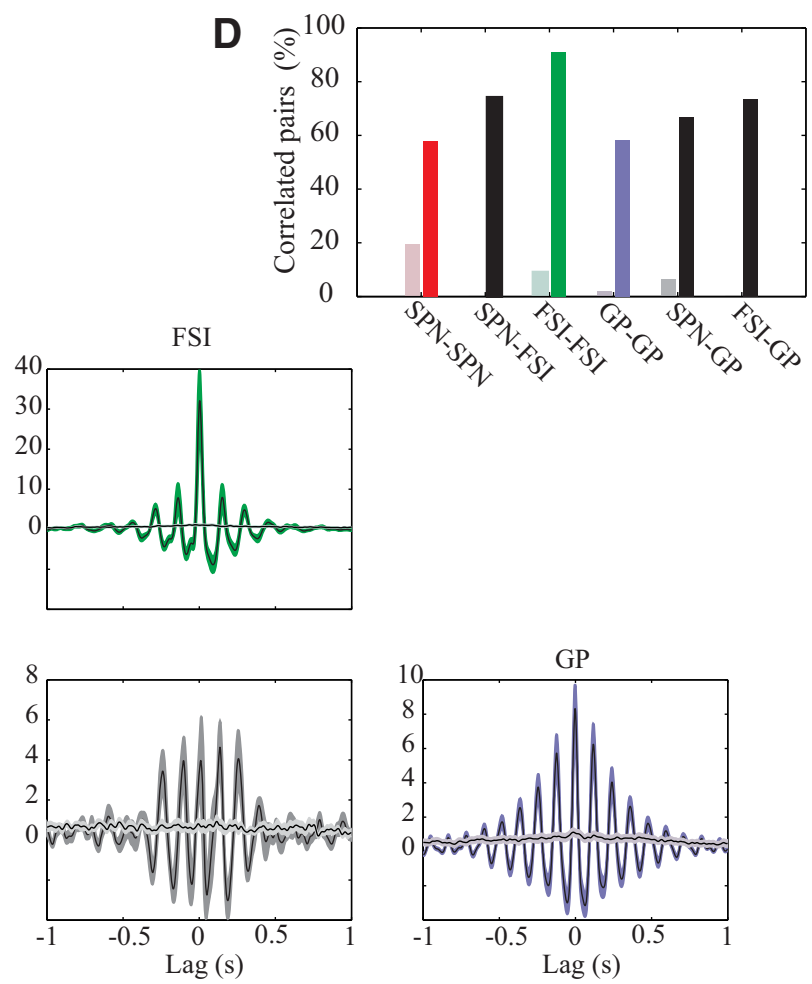

Figure 5. Correlated neuronal activity following IEM-1460 injection. $A, C$, Mean coherence $(A)$ and rate normalized cross-correlation $(C)$ within and between neuronal population pairs before and after IEM-1460 microinjection (black, mean; background, \pm SEM). $\boldsymbol{B}, \boldsymbol{D}$, Percentages of significantly coherent $(\boldsymbol{B})$ and correlated $(\boldsymbol{D})$ pairs. Interactions within neuronal populations are shown in red (SPN), green (FSI), and purple (GP). Interactions between neuronal populations are in gray.

(Figure legend continued.) within each population. The vector sum of the phase locking for each population is indicated by an arrow. For display purposes, the length of the arrows has been reduced by a factor of $5 .{ }^{*} p<0.01 ;{ }^{* *} p<0.001$.
Inactivation of M1 leads to a reduction in LFP oscillations and the suppression of tremor

The effect of cortical input on the IEM-1460-induced tremor and oscillations was assessed using muscimol injections into the somatotopic location within M1 corresponding to the location of the tremor expression (forelimb area; five animals, 17 sessions). 
A

B
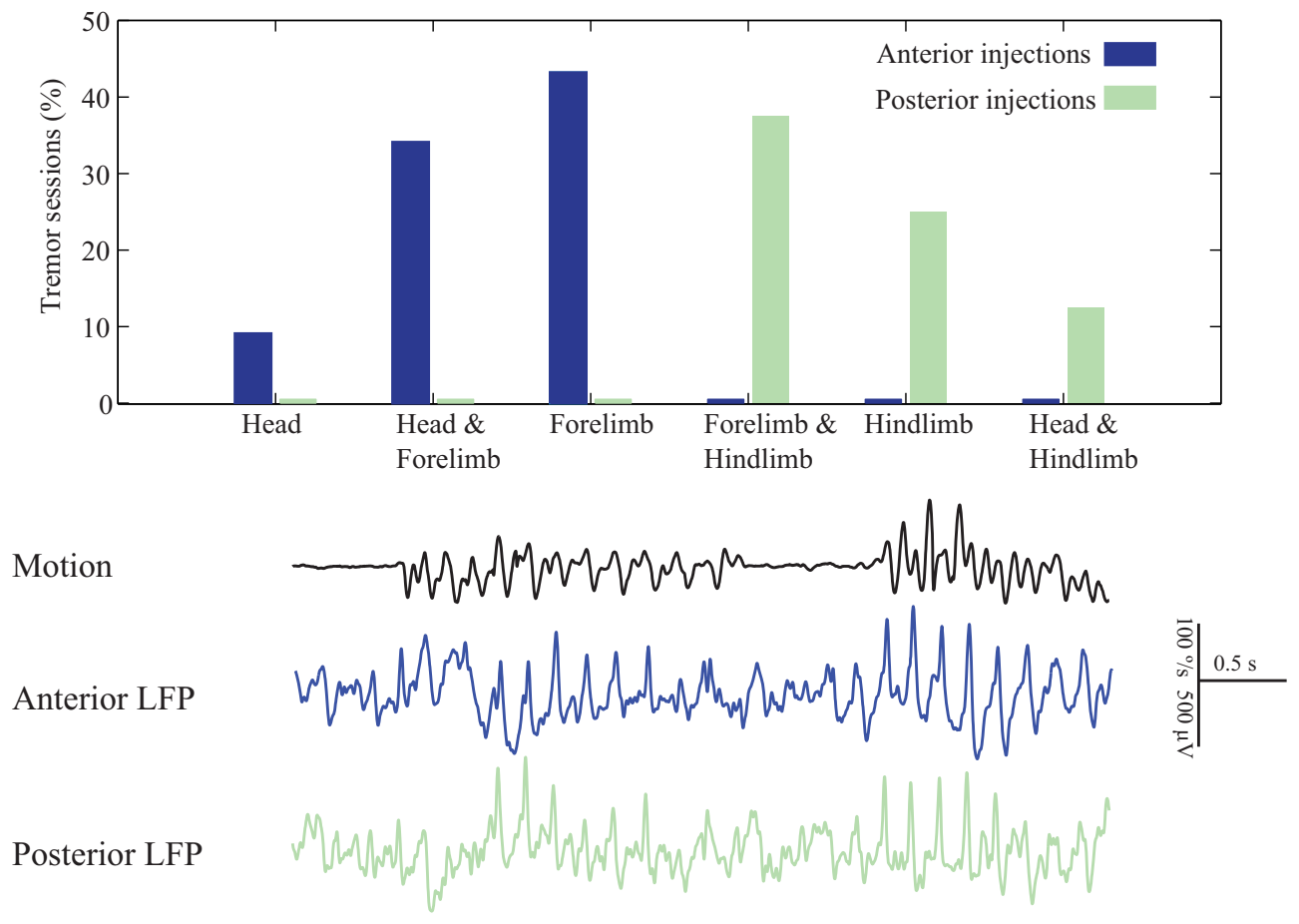

C

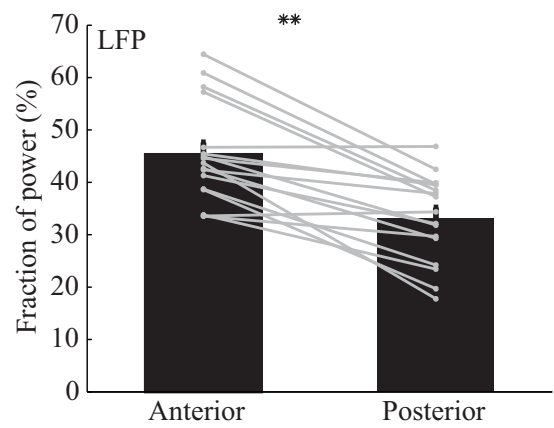

D

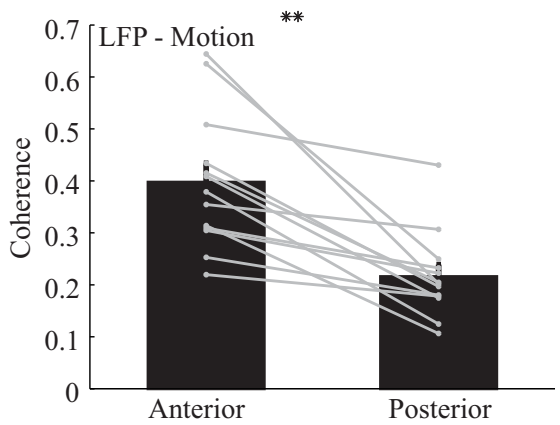

Figure 6. Somatotopic organization of the tremor and the associated neural activity. A, Percentages of IEM-1460 microinjections to the anterior (dark blue) or posterior (light green) striatum inducing tremor in different body parts. $\boldsymbol{B}$, Example of a gyroscope signal (black) during a tremor episode and two simultaneously recorded LFP traces from an anterior location (dark blue) close to the injection area and a posterior location (light green) $1.5 \mathrm{~mm}$ posterior to the anterior location. $C$, Fractions of the power spectrum in the $5-8 \mathrm{~Hz}$ band in the anterior and posterior $\mathrm{LFP}$, where each line represents a single session. $\boldsymbol{D}$, Coherence between the LFP in the anterior and posterior locations and the gyroscope signal. Each line represents a single session. ${ }^{* *} p<0.001$.

Muscimol was injected $\sim 20$ min after the appearance of tremor episodes following IEM-1460 injection in the anterior DLS. The tremor and the overall movement were largely reduced for the rest of the session, with a latency of 5-10 min after the muscimol injection (Fig. $7 A, B$, top). Concurrently, the oscillations in the LFP declined (Fig. $7 A, B$, bottom). Analysis of the spectral characteristics of single-cell activity $(n=38)$ revealed that most neurons exhibited a reduction in the LFP spike train phase locking in the $5-8 \mathrm{~Hz}$ band (Fig. $7 C, D$ ), and a significant reduction in overall oscillation power $(p<0.001$, WSRT).

\section{Discussion}

Selective inhibition of FSIs led to the formation of tremor, which appeared in the body part corresponding to the somatotopic location of the injection of IEM-1460 within the DLS. The tremor was episodic in nature, with both the duration of the tremor episodes and the intervals between them behaving like a memoryless random process. The tremor whose frequency ranged between $5-8 \mathrm{~Hz}$ was symmetric in nature and contained significant power in its harmonics. Tremor was associated with coherent
LFP oscillations throughout the striatum and GP. As a population, FSIs reduced their firing rate due to their direct inhibition, whereas the indirectly affected neurons, both SPNs and GP neurons, did not change their mean rate. The activity of neurons in both the striatum and GP became temporally correlated, and their firing pattern became oscillatory and coherent with both the LFP and the movement. The activity also became spatially correlated, and could be categorized into two interaction types: an oscillatory interaction that was apparent also in the GP and a nonoscillatory interaction in the striatum that was not evident in the GP. Changes in neuronal activity patterns were predominant in the local environment of the injection compared to remote areas encoding nontremulous body parts. The subsequent reduction of the excitatory corticostriatal input to the striatum resulted in the disappearance of the tremor, a reduction in the LFP oscillations, and the reversal of the temporal and spatial neuronal correlations.

Abnormal movements were observed previously in both mice and rats following DLS injections of IEM-1460. The movements 
A
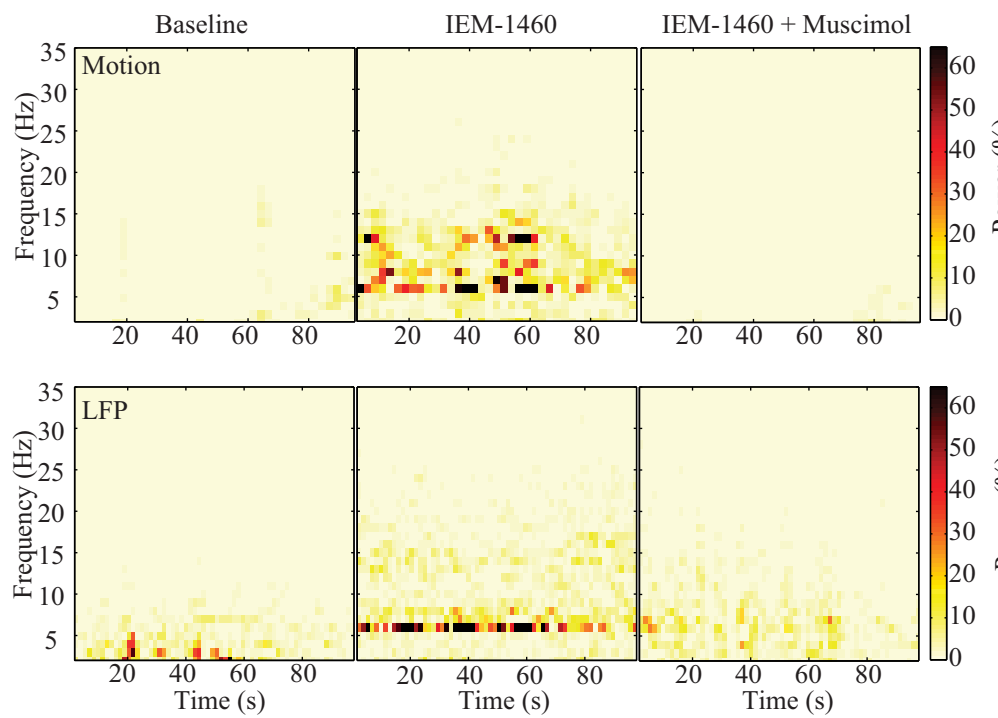

B
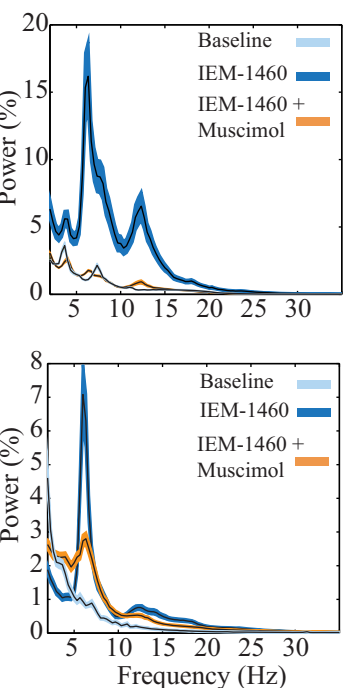

D

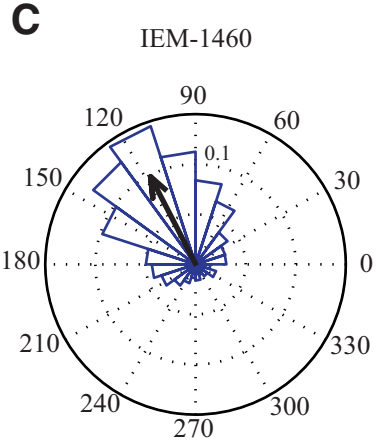

IEM-1460 + Muscimol
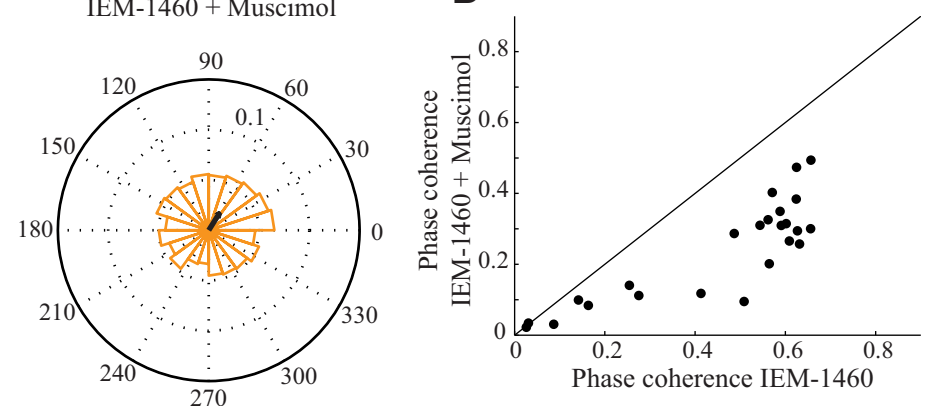

Figure 7. Injection of muscimol to M1 leads to the reduction of LFP oscillations and the disappearance of tremor. $A$, Spectrogram of the gyroscope (top) and LFP (bottom) signals in a single session with IEM-1460 microinjection to the striatum followed by a muscimol microinjection to M1. B, Mean power spectrum of the gyroscope (top) and LFP (bottom) of all the sessions after IEM-1460 microinjection (blue) and after the subsequent muscimol microinjection (orange). C, Phase distribution of a single neuron following IEM-1460 microinjection and the subsequent muscimol microinjection. The black arrow represents the vector sum of the distribution. For display purposes, the length of the arrows has been reduced by a factor of 5 . $\boldsymbol{D}$, Phase coherence of all the neurons to LFP signal after IEM-1460, before and after the muscimol microinjection.

ranged from dystonia and dyskinesia, whose severity was scored manually, in mice (Gittis et al., 2011) to abnormal movements, whose magnitude was assessed using video analysis and generally termed intermittent fast movements, in rats (Klaus and Plenz, 2016). The difference in the movement abnormalities may be attributed to the difference in the species and the IEM-1460 doses. The use of high-speed kinematic measurements in the current study enabled the detailed analysis of these movements for the first time. Abnormal movement was episodic in nature and consisted of symmetrical movements resembling tremor (Heimer et al., 2006) that were very different from the jerky asymmetrical movements typical of motor tics (McCairn et al., 2009). The tremor was typically expressed during rest and resembled the expression of parkinsonian tremor (Parkinson, 1817). The base frequencies and the harmonics of the observed tremor resembled the spectral characteristics of tremor seen in Parkinson's disease and dystonia albeit around higher main frequencies (Silberstein et al., 2003).

Abnormal low-frequency LFP oscillations appear in the BG during multiple normal and abnormal states. In Parkinson's disease, low-frequency oscillations $(4-5 \mathrm{~Hz})$ appear during tremor episodes. Similar to our results, parkinsonian LFP oscillations show intermittent coherence with the tremor and high coherence values for the harmonics (Wang et al., 2005). Low-frequency LFP oscillations $(8-10 \mathrm{~Hz})$ appear in the normal rat and are termed high-voltage spindles (HVSs). This activity appears sporadically in the normal state during rest and is not accompanied by tremor (Klingberg and Pickenhain, 1968). HVSs magnitude and duration increase dramatically following dopamine depletion in the rat 6-OHDA model (Dejean et al., 2008) or application of $\mathrm{D}_{2}$ antagonists (Yael et al., 2013). The oscillations observed in this study resemble certain properties of HVSs such as their appearance primarily during rest, phase locking of both SPNs and FSIs to the LFP, and a reduction in FSI firing rate. However, the temporal shape of the oscillations was more symmetric compared to HVSs, the frequency was typically lower, and, most importantly, there was an association with large amplitude tremor, which is typically missing during HVSs. Despite these differences, the common properties of BG oscillations may hint at common mechanisms for the breakdown of striatal processing and the formation of oscillations, potentially through thalamic and cortical mechanisms (Buzsáki et al., 1990; Berke et al., 2004).

In line with previous studies (Gittis et al., 2011), we observed a decrease in the mean firing rate of FSIs but not in the activity of SPNs. However, in this study, we showed that the dominant change to striatal neuronal activity lay in the firing pattern of the striatum and its downstream target. FSIs exert powerful feedforward inhibition on SPNs that can control their spike timing 
(Koós and Tepper, 1999; Mallet et al., 2005), enabling the substantial modulation of the firing pattern observed in our data. The neuronal activity in the GP revealed a complex transfer of activity from the striatum: the firing rate was unaltered, mirroring the stable rate of the striatal projection neurons, but the firing pattern became oscillatory and coherent, mirroring the striatal coherent oscillatory activity. Nevertheless, the bursty, highly correlated activity of striatal neurons was not associated with similar changes in GP activity as was observed previously during Parkinson's disease (Levy et al., 2002). The widely coherent activity in the striatum across a wide range of frequencies was filtered by the $\mathrm{GP}$, resulting in the propagation downstream of the primary tremor frequency and its harmonics alone. This highly correlated BG activity is common in multiple BG disorders such as Parkinson's disease (Levy et al., 2002) and dystonia (Schrock et al., 2009) as well as in experimental models of chorea (Bronfeld et al., 2010), tics (McCairn et al., 2009), and dyskinesia (Meissner et al., 2006). This correlated activity contrasts sharply with the uncorrelated neuronal activity that is typical of the normal basal ganglia. This uncorrelated normal neuronal activity is unexpected given the massive convergence of the cortico-basal ganglia pathway, and its breakdown in multiple disorders hints at an active decorrelation process (Bronfeld and Bar-Gad, 2011). This decorrelation process may be achieved via the SPN collateral (feedback) or, as supported by the current results, FSI (feedforward) inhibition and aid maximal information transfer in the corticobasal ganglia pathway (Bar-Gad et al., 2003).

Tremor was somatotopically organized and adhered to the organization shown in the normal striatum (Cospito and KultasIlinsky, 1981; Ebrahimi et al., 1992; Brown et al., 1998). Tics evoked using bicuculline injection into the DLS were consistent with the same organization and elicited localized forelimb movement following anterior injections (Bronfeld et al., 2013). Changes in neuronal activity patterns were predominant in the local environment of the injection and were weaker in remote areas encoding nontremulous body parts, in line with the results that emerged after bicuculline injection (Worbe et al., 2009; Bronfeld et al., 2011). However, the differences in LFP oscillations may not necessarily reflect a local process of oscillation generation, but may rather result from passive conductance from a remote area (Lalla et al., 2017). The highly organized appearance of the tremor and the focal changes in neuronal activity are consistent with the somatotopic organization of the striatum but are not straightforward to interpret when examining the organization of the FSI network since FSIs are interconnected through gap junctions, which are presumed to allow for the formation of large-scale coordinated networks (Kita et al., 1990). These neurons have large axonal fields that cross somatotopic areas (Bevan et al., 1998). These anatomical and connectivity properties generated the hypothesis that FSIs serve as a source of coordinated broad inhibition (Plenz, 2003). Our results, as well as previous reports that failed to demonstrate a synchronized FSI population response to behavioral task (Berke, 2008), suggest a nonglobal FSI effect rather than the formation of a coordinated inhibitory network within the striatum. This role of non-FSI inhibitory input is evident from the fundamental differences between the effects of selective blocking of FSIs compared to the nonselective antagonism of $\mathrm{GABA}_{\mathrm{A}}$ transmission. Complete blocking of the inhibition results in jerky, asymmetrical movements (tics; McCairn et al., 2009; Israelashvili and Bar-Gad, 2015) whose neuronal correlates persist following inactivation of corticostriatal input (Muramatsu et al., 1990; Pogorelov et al., 2015). The interplay of the GABAergic transmission from different sources thus plays a key role in the maintenance of normal movement, and the specifics of its breakdown determine the properties of the resulting clinical symptoms.

Our results position the FSI population as a key player in balancing cortical input in the striatal microcircuit by contributing to the decorrelation process as this input converges. Previous results support the involvement of FSIs in balancing and integrating cortical input and have shown that individual striatal FSIs receive direct converging glutamatergic synapses from multiple cortical regions (Ramanathan et al., 2002), FSIs are more responsive to cortical inputs than SPNs (Parthasarathy and Graybiel, 1997), and they respond to cortical stimulation with brief highfrequency bursts (Kita, 1993). In turn, these interneurons provide powerful GABAergic input to a large number of nearby SPNs (Koós and Tepper, 1999) via synapses on cell bodies and proximal dendrites (Bennett and Bolam, 1994). This allows for a strong, widespread feedforward inhibition. Our results demonstrate that focal FSI manipulation is sufficient to alter the excitation/inhibition balance in the striatum, a process that can be reversed by reducing the incoming excitation to the striatal network. This positions FSIs not merely as a coordinated network that synchronizes SPN activity, but rather as critical nodes in balancing the flow of cortical input and governing the decorrelation process in the striatum.

\section{References}

Alexander GE, DeLong MR, Strick PL (1986) Parallel organization of functionally segregated circuits linking basal ganglia and cortex. Annu Rev Neurosci 9:357-381. CrossRef Medline

Bar-Gad I, Morris G, Bergman H (2003) Information processing, dimensionality reduction and reinforcement learning in the basal ganglia. Prog Neurobiol 71:439-473. CrossRef Medline

Bennett BD, Bolam JP (1994) Synaptic input and output of parvalbuminimmunoreactive neurons in the neostriatum of the rat. Neuroscience 62:707-719. CrossRef Medline

Berke JD (2008) Uncoordinated firing rate changes of striatal fast-spiking interneurons during behavioral task performance. J Neurosci 28:1007510080. CrossRef Medline

Berke JD (2011) Functional properties of striatal fast-spiking interneurons. Front Syst Neurosci 5:45. Medline

Berke JD, Okatan M, Skurski J, Eichenbaum HB (2004) Oscillatory entrainment of striatal neurons in freely moving rats. Neuron 43:883-896. CrossRef Medline

Bernheimer H, Birkmayer W, Hornykiewicz O, Jellinger K, Seitelberger F (1973) Brain dopamine and the syndromes of Parkinson and Huntington clinical, morphological and neurochemical correlations. J Neurol Sci 20:415-455. CrossRef Medline

Bevan MD, Booth PA, Eaton SA, Bolam JP (1998) Selective innervation of neostriatal interneurons by a subclass of neuron in the globus pallidus of the rat. J Neurosci 18:9438-9452. Medline

Bronfeld M, Bar-Gad I (2011) Loss of specificity in basal ganglia related movement disorders. Front Syst Neurosci 5:38. Medline

Bronfeld M, Belelovsky K, Erez Y, Bugaysen J, Korngreen A, Bar-Gad I (2010) Bicuculline-induced chorea manifests in focal rather than globalized abnormalities in the activation of the external and internal globus pallidus. J Neurophysiol 104:3261-3275. CrossRef Medline

Bronfeld M, Belelovsky K, Bar-Gad I (2011) Spatial and temporal properties of tic-related neuronal activity in the cortico-basal ganglia loop. J Neurosci 31:8713-8721. CrossRef Medline

Bronfeld M, Yael D, Belelovsky K, Bar-Gad I (2013) Motor tics evoked by striatal disinhibition in the rat. Front Syst Neurosci 7:50. Medline

Brown LL, Smith DM, Goldbloom LM (1998) Organizing principles of cortical integration in the rat neostriatum: corticostriate map of the body surface is an ordered lattice of curved laminae and radial points. J Comp Neurol 392:468-488. CrossRef Medline

Buzsáki G, Smith A, Berger S, Fisher LJ, Gage FH (1990) Commentary mal epilepsy and parkinsonian tremor: hypothesis of a common. Neuroscience 36:1-14. CrossRef Medline 
Cospito JA, Kultas-Ilinsky K (1981) Synaptic organization of motor corticostriatal projections in the rat. Exp Neurol 72:257-266. Medline

Dejean C, Gross CE, Bioulac B, Boraud T (2008) Dynamic changes in the cortex-basal ganglia network after dopamine depletion in the rat. J Neurophysiol 100:385-396. CrossRef Medline

Ebrahimi A, Pochet R, Roger M (1992) Topographical organization of the projections from physiologically identified areas of the motor cortex to the striatum in the rat. Neurosci Res 14:39-60. Medline

Gernert M, Hamann M, Bennay M, Löscher W, Richter A (2000) Deficit of striatal parvalbumin-reactive GABAergic interneurons and decreased basal ganglia output in a genetic rodent model of idiopathic paroxysmal dystonia. J Neurosci 20:7052-7058. Medline

Gittis AH, Leventhal DK, Fensterheim BA, Pettibone JR, Berke JD, Kreitzer AC (2011) Selective inhibition of striatal fast-spiking interneurons causes dyskinesias. J Neurosci 31:15727-15731. CrossRef Medline

Graveland GA, Williams RS, DiFiglia M (1985) Evidence for degenerative and regenerative changes in neostriatal spiny neurons in Huntington's disease. Science 227:770-773. CrossRef Medline

Heimer G, Rivlin-Etzion M, Bar-Gad I, Goldberg JA, Haber SN, Bergman H (2006) Dopamine replacement therapy does not restore the full spectrum of normal pallidal activity in the 1-methyl-4-phenyl-1,2,3,6-tetrahydropyridine primate model of parkinsonism. J Neurosci 26:81018114. CrossRef Medline

Israelashvili M, Bar-Gad I (2015) Corticostriatal divergent function in determining the temporal and spatial properties of motor tics. J Neurosci 35:16340-16351. CrossRef Medline

Kalanithi PS, Zheng W, Kataoka Y, DiFiglia M, Grantz H, Saper CB, Schwartz ML, Leckman JF, Vaccarino FM (2005) Altered parvalbumin-positive neuron distribution in basal ganglia of individuals with Tourette syndrome. Proc Natl Acad Sci U S A 102:13307-13312. CrossRef Medline

Kita H (1993) GABAergic circuits of the striatum. Prog Brain Res 99:51-72. CrossRef Medline

Kita H, Kosaka T, Heizmann CW (1990) Parvalbumin-immunoreactive neurons in the rat neostriatum: a light and electron microscopic study. Brain Res 536:1-15. CrossRef Medline

Klaus A, Plenz D (2016) A low-correlation resting state of the striatum during cortical avalanches and its role in movement suppression. PLoS Biol 14:1-30. Medline

Klingberg F, Pickenhain L (1968) Occurrence of "spindle discharges" in the rat in relation to behavior. Acta Biol Med Ger 20:45-54. Medline

Koós T, Tepper JM (1999) Inhibitory control of neostriatal projection neurons by GABAergic interneurons. Nat Neurosci 2:467-472. CrossRef Medline

Lalla L, Rueda Orozco PE, Jurado-Parras MT, Brovelli A, Robbe D (2017) Local or not local: investigating the nature of striatal theta oscillations in behaving rats. eNeuro 4:ENEURO.0128-17.2017. Medline

Levy R, Hutchison WD, Lozano AM, Dostrovsky JO (2002) Synchronized neuronal discharge in the basal ganglia of parkinsonian patients is limited to oscillatory activity. J Neurosci 22:2855-2861. Medline

Luk KC, Sadikot AF (2001) GABA promotes survival but not proliferation of parvalbumin-immunoreactive interneurons in rodent neostriatum: an in vivo study with stereology. Neuroscience 104:93-103. CrossRef Medline

Magazanik LG, Buldakova SL, Samoilova MV, Gmiro VE, Mellor IR, Usherwood PN (1997) Block of open channels of recombinant AMPA receptors and native AMPA/kainate receptors by adamantane derivatives. J Physiol 505:655-663. CrossRef Medline

Mallet N, Le Moine C, Charpier S, Gonon F (2005) Feedforward inhibition of projection neurons by fast-spiking GABA interneurons in the rat striatum in vivo. J Neurosci 25:3857-3869. CrossRef Medline
Mallet N, Micklem BR, Henny P, Brown MT, Williams C, Bolam JP, Nakamura KC, Magill PJ (2012) Dichotomous organization of the external globus pallidus. Neuron 74:1075-1086. CrossRef Medline

McCairn KW, Bronfeld M, Belelovsky K, Bar-Gad I (2009) The neurophysiological correlates of motor tics following focal striatal disinhibition. Brain 132:2125-2138. CrossRef Medline

Meissner W, Ravenscroft P, Reese R, Harnack D, Morgenstern R, Kupsch A, Klitgaard H, Bioulac B, Gross CE, Bezard E, Boraud T (2006) Increased slow oscillatory activity in substantia nigra pars reticulata triggers abnormal involuntary movements in the 6-OHDA-lesioned rat in the presence of excessive extracellular striatal dopamine. Neurobiol Dis 22:586-598. CrossRef Medline

Muramatsu S, Yoshida M, Nakamura S (1990) Electrophysiological study of dyskinesia produced by microinjection of picrotoxin into the striatum of the rat. Neurosci Res 7:369-380. CrossRef Medline

Oorschot DE (1996) Total number of neurons in the neostriatal, pallidal, subthalamic, and substantia nigral nuclei of the rat basal ganglia: a stereological study using the cavalieri and optical disector methods. J Comp Neurol 366:580-599. CrossRef Medline

Parkinson J (1817) An essay on the shaking palsy. London: Sherwood, Neely and Jones.

Parthasarathy HB, Graybiel AM (1997) Cortically driven immediate-early gene expression reflects modular influence of sensorimotor cortex on identified striatal neurons in the squirrel monkey. J Neurosci 17:24772491. Medline

Plenz D (2003) When inhibition goes incognito: feedback interaction between spiny projection neurons in striatal function. Trends Neurosci 26 : 436-443. CrossRef Medline

Pogorelov V, Xu M, Smith HR, Buchanan GF, Pittenger C (2015) Corticostriatal interactions in the generation of tic-like behaviors after local striatal disinhibition. Exp Neurol 265:122-128. CrossRef Medline

Ramanathan S, Hanley JJ, Deniau JM, Bolam JP (2002) Synaptic convergence of motor and somatosensory cortical afferents onto GABAergic interneurons in the rat striatum. J Neurosci 22:8158-8169. Medline

Rosenberg JR, Amjad AM, Breeze P, Brillinger DR, Halliday DM (1989) The Fourier approach to the identification of functional coupling between neuronal spike trains. Prog Biophys Mol Biol 53:1-31. CrossRef Medline

Schrock LE, Ostrem JL, Turner RS, Shimamoto SA, Starr PA (2009) The subthalamic nucleus in primary dystonia: single-unit discharge characteristics. J Neurophysiol 102:3740-3752. CrossRef Medline

Silberstein P, Kühn AA, Kupsch A, Trottenberg T, Krauss JK, Wöhrle JC, Mazzone P, Insola A, Di Lazzaro V, Oliviero A, Aziz T, Brown P (2003) Patterning of globus pallidus local field potentials differs between Parkinson's disease and dystonia. Brain 126:2597-2608. CrossRef Medline

Tunstall MJ, Oorschot DE, Kean A, Wickens JR (2002) Inhibitory interactions between spiny projection neurons in the rat striatum. J Neurophysiol 88:1263-1269. CrossRef Medline

Wang S-Y, Aziz TZ, Stein JF, Liu X (2005) Time-frequency analysis of transient neuromuscular events: dynamic changes in activity of the subthalamic nucleus and forearm muscles related to the intermittent resting tremor. J Neurosci Methods 145:151-158. CrossRef Medline

Worbe Y, Baup N, Grabli D, Chaigneau M, Mounayar S, McCairn K, Féger J, Tremblay L (2009) Behavioral and movement disorders induced by local inhibitory dysfunction in primate striatum. Cereb Cortex 19:18441856. CrossRef Medline

Yael D, Zeef DH, Sand D, Moran A, Katz DB, Cohen D, Temel Y, Bar-Gad I (2013) Haloperidol-induced changes in neuronal activity in the striatum of the freely moving rat. Front Syst Neurosci 7:110. Medline 